\title{
Acute Psychosis related Pituitary Haemorrhage
}

\author{
A Ragbir, K Obuobie
}

Royal Gwent Hospital, Newport, Aneurin Bevan University Health Board

\section{Introduction}

Pituitary apoplexy (PA) is a rare and potentially life threatening clinical syndrome as a result of haemorrhage or infarction in the pituitary ${ }^{1}$. It has been described mostly in association with a pituitary adenoma, more likely in macroadenomas, but only in isolated cases with a structurally normal pituitary gland. The pathophysiological mechanism underlying traumatic pituitary apoplexy has not been established and is rarely described ${ }^{2}$. Neuropsychiatric symptoms as a presentation of hypopituitarism is also very rare $^{3}$.

\section{Case History}

44 year old retired male athlete. Fit and Well. Not on any medication.

\section{Day -7}

Long Shower $>2$ hrs

"Unable to get temperature right."

Screamed out and found shivering with bruise on forehead. Acted Bizarrely. "I will cure them."

Left house and went by himself to a "safe place."

\section{Day -6}

Wife called by Police

Witnessed to be behaving bizarrely in car.

9 Police officers required to restrain him. Taken to hospital.

CT Head: Normal.

Hallucinating, jerking movements and further bizarre

behaviour.

Day -5

Discharged from hospital

Day -5 to -1

At home more bizarre behaviour

Flight of ideas, agitation and paranoia.

"Children were possessed"

Day -1

Sectioned under Mental Health Act.

Transferred to Mental health hospital.

Day 0*

Developed GTC seizure and fever

Transferred to DGH: Royal Gwent.

History: no recollection of events. History from wife. C/O severe

headache and extreme thirst. Leaving cubicle frequently to micturate. Normal Observations. Oriented.

Examination: No neck stiffness. No photophobia. Lateral tongue bite. Normal neurology. Normal extraocular movements and visual fields.

\section{Day 0 to Discharge}

Lumbar puncture: Normal.

MRI: revealed high T1 signal from the right half of the moderately

enlarged pituitary gland suggestive of a small bleed within the gland.

Diagnosis: Pituitary Apoplexy.

Started on empiric hydrocortisone.

After acute phase SST performed: baseline $205 \mathrm{nmol} / \mathrm{L}$ and 408 (30

mins). (Abbott assay N; 30min>450nmol/L).

Rest of pituitary profile normal.

\section{Follow up}

1 Month post Discharge: SST baseline $228 \mathrm{nmol} / \mathrm{L}$ and 30 mins

$372 \mathrm{nmol} / \mathrm{L}$. Pituitary profile remained normal.

He made a good recovery with appropriate management of his acute psychosis and maintenance hydrocortisone replacement.

\section{Discussion}

PA most commonly is associated with a bleed into an adenoma, however pituitary apoplexy may also occur in non-adenomatous or even within a normal pituitary gland especially during pregnancy ${ }^{1}$. Pituitary adenomas are prone to bleed and undergo infarction and necrosis. This is because adenomas are predominantly supplied by a direct blood supply, rather than the portal system in the normal pituitary. In addition, prolactinomas contain arteries not found in a normal anterior pituitary. These are likely the reasons pituitary apoplexy is rarely reported in a normal pituitary. Diagnosis of PA is frequently missed, not only because of its low incidence, but also the presentation can be slowly progressive as in our case. This subacute presentation can be dependent upon the extent of bleeding as well as the degree of oedema and necrosis ${ }^{4}$.

In a recent literature review, only 13 post-traumatic pituitary apoplexy cases were identified from 1983 to $2016^{2}$. The mechanism underlying post traumatic pituitary apoplexy has not been established. Possible hypothesis including traumatic shearing forces causing the destruction of the pituitary stalk and lead to the consequent blockage of pituitary portal vascularization ${ }^{5}$ or alteration of the venous vascularization pattern following haemorrhage encouraging ischemic-haemorrhagic occurrences ${ }^{6}$.

In traumatic cases, PA symptoms usually become evident after few hours, with a mean delay of presentation of 14 days, whereas in some cases can even be up to 2 months ${ }^{2}$. High temperatures in PA could be thought to be a sign of infection and may delay the diagnosis, but is in fact a typical finding in patients with $\mathrm{PA}^{7,8}$

Psychotic presentations following panhypopituitarism has been described from various aetiologies including an ectopic posterior pituitary, Russell's Viper Bite, Sheehan's syndrome, Traumatic Brain Injury (TBI), and after glucocorticoid therapy ${ }^{9-13}$.The pathogenesis of psychosis in hypopituitarism is postulated to be a result of interactions between pituitary hormones and the dominant neurotransmitters ${ }^{3}$. Krishnamurthy et al. (2013) in a post mortem study of schizophrenic subjects, molecular changes were identified in the pituitary gland with differentially expressed molecules including hypothalamic-pituitary-adrenal axis-associated constituents such as cortisol, pro-adrenocorticotropic hormone, arginine vasopressin precursor, agouti-related protein, growth hormone, prolactin and secretagogin, as well as molecules associated with lipid transport and metabolism. They concluded that these hormones may present some diagnostic utility with further research in schizophrenia ${ }^{14}$

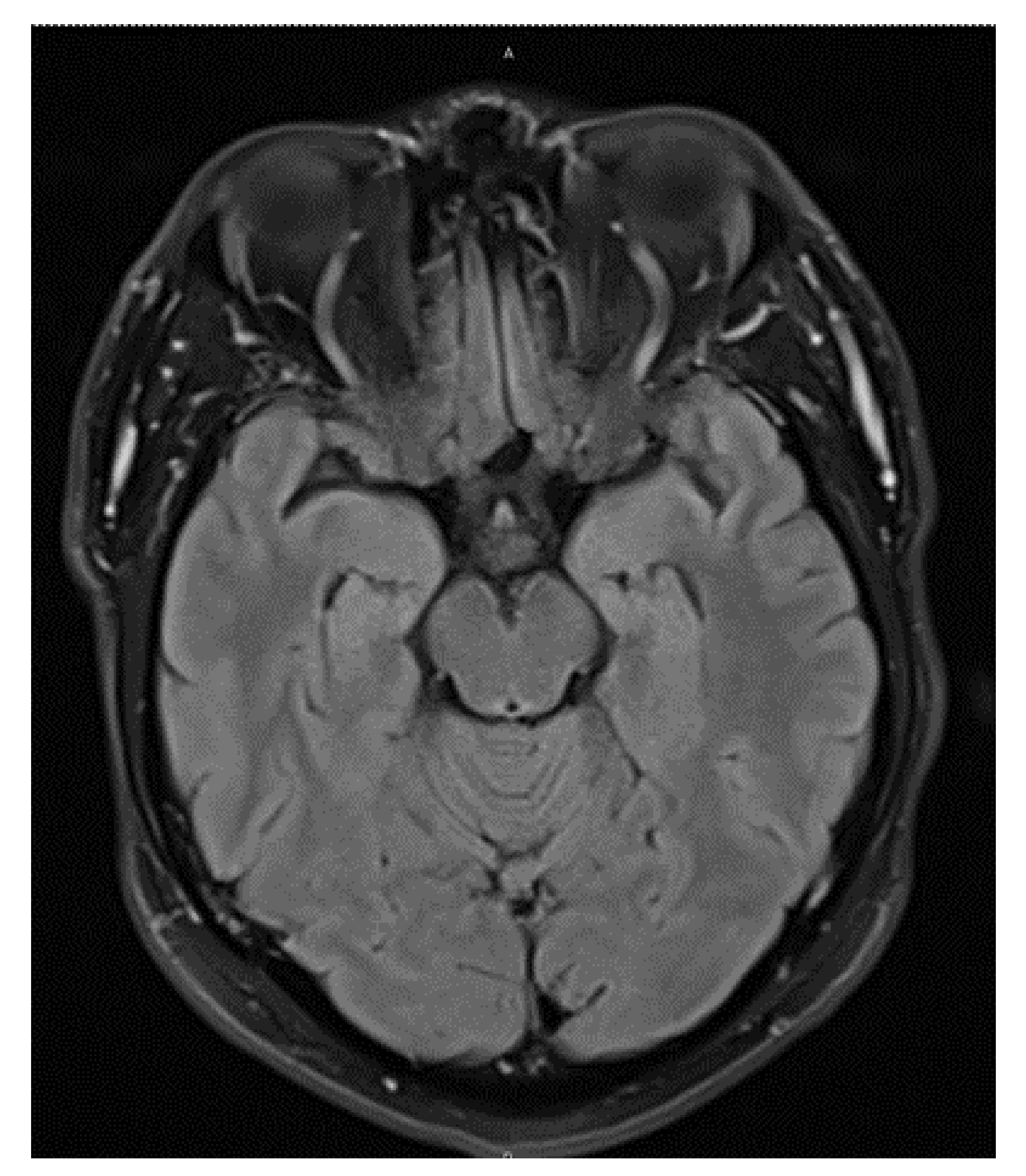

\section{Conclusion}

MRI of the pituitary should be obtained at 3-6 month intervals until the anatomy is stable and then yearly for 5 years. A month post discharge from the hospital and recovery from the acute event, repeat endocrine testing to determine if the endocrine defects persist to confirm whether the patient needs to remain on life-long hormone replacement ${ }^{15}$.

It is important to think of PA even after minimal head trauma especially in the setting of abnormal behaviour. The presentation may be subacute and MR imaging should be done even in the presence of normal $\mathrm{CT}$.

\section{References}

Ranabir S, Baruah MP. Pituitary apoplexy. Indian J Endocrinol Metab. 2011:15 Supp I 3(Suppl3):S188-96.

Billeci D, Marton E, Giordan E. Post-traumatic pituitary apoplexy: Case presentation and review of literature. Interdisciplinary Neurosurgery. 2017:7, Pages 4-8

Jegede $\mathrm{O}$, Jeyakumar A, Balakumar T, et al. Neuropsychiatric Manifestations in a Patient with Panhypopituitarism. Case Rep Psychiatry. 2017;2017:5082687.

4. Onesti ST, Wisniewski T, Post KD. Clinical versus subclinical pituitary apoplexy: presentation surgical management and outcome in 21 patients. Neurosurgery 1990;26:980-6. 5.O. Holness, F.A. Ogundimu, R.A. Langille. Pituitary apoplexy following closed head trauma. Case report J. Neurosurg., 59 (4) (1983), pp. 677-679

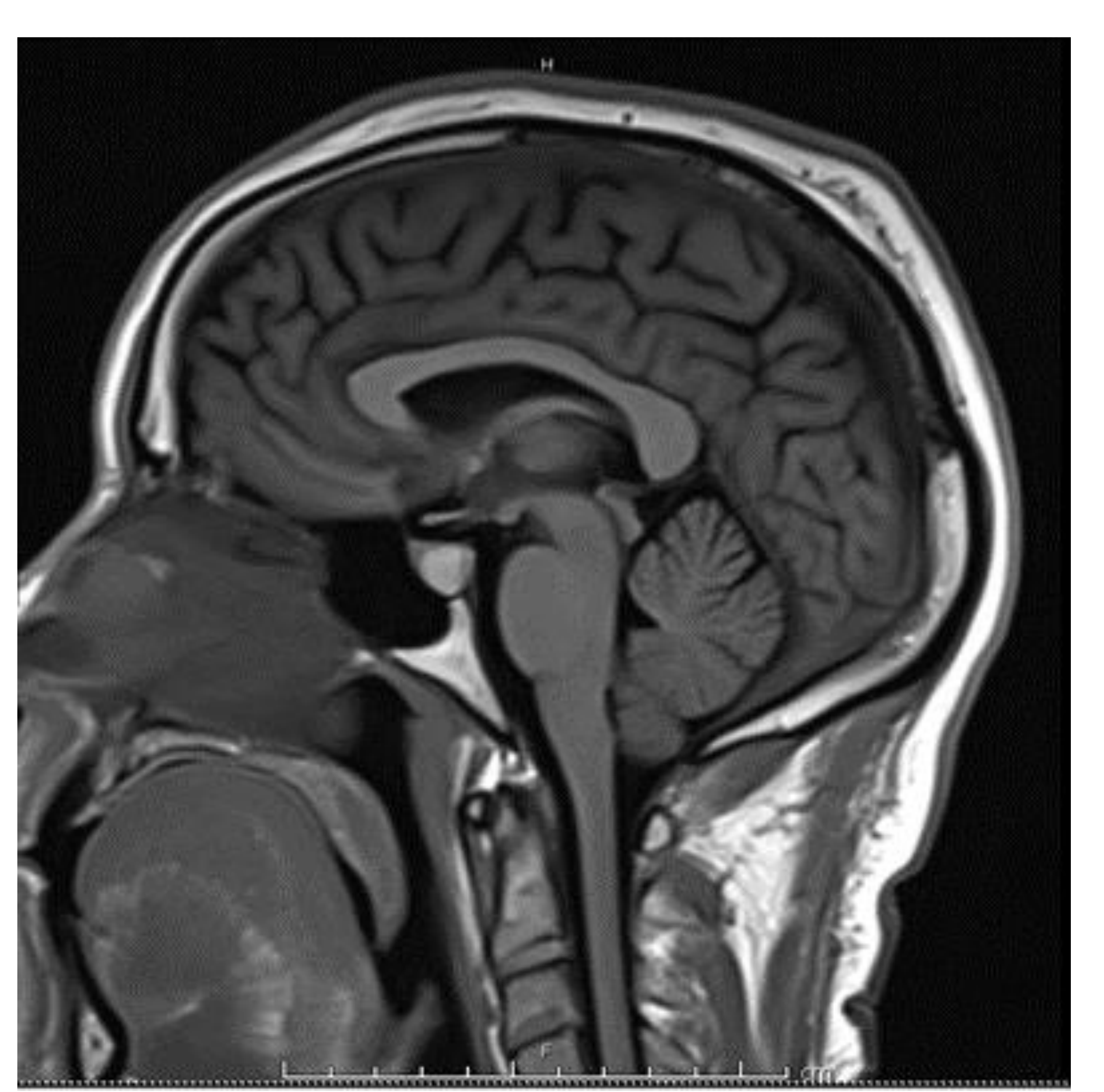

H. Uchiyama, S. Nishizawa, A. Satoh, T. Yokoyama, K. Uemura. Post-traumatic pituitary apoplexy-two case reports. Neurol. Med. Chir., 39 (1) (1999), pp. 36-39

Smidt MH, Vliet AV, Wesseling P, J. de Vries, Twickler TB, P.E. Vos Pituitary apoplexy after mild head injury misinterpreted as bacterial meningitis. Eur. J. Neurol, 14 (7) (2007), pp. e7-e8

C. Lin, T. Jen-Ho, Y. Muh-Yong, J. Cherng-Lan, H. Sheng-HuangPituitary apoplexy following mild head injury mimicking bacterial meningitis. J. Chin. Oncol., 25 (2) (2009), pp. 137-141 Baharom M. A., Abdullah M. F. I. L., Wahab S. Panhypopituitarism and psychosis: issues and challenges in management. International Medical Journal. 2016;23(2):132-133. 10. Ratnakaran B., Punnoose V. P., Das S., Kartha A. Psychosis in secondary empty sella syndrome following a Russells viper bite. Indian Journal of Psychological Medicine. 2016;38(3):254-256. doi: 10.4103/0253-7176.183079

11. Tikir B., Goka E., Aydemir M. C., Gurkan S. Psychotic disorder and sheehans syndrom etiology or comorbidity? A case report. Turkish Journal of Psychiatry. 2015;26(2) 12.Chang Y.-C., Tsai J.-C., Tseng F.-Y. Neuropsychiatric disturbances and hypopituitarism after traumatic brain injury in an elderly man. Journal of the Formosan Medical Association. 2006;105(2):172-176. doi: 10.1016/s0929-6646(09)60341-7.

3.Hong S. I., Cho D. H., Kang H. C., Chung D. J., Chung M. Y. Acute onset of steroid psychosis with very low dose of prednisolone in Sheehan's syndrome. Endocrine Journal. 2006;53(2):255-258. doi: 10.1507/endocri.53.255.

4.Krishnamurthy D., Harris L. W., Levin Y., et al. Metabolic, hormonal and stress-related molecular changes in post-mortem pituitary glands from schizophrenia subjects. The World Journal of Biological Psychiatry. 2013;14(7):478-489. doi: 10.3109/15622975.2011.601759. 5.Rajasekaran, S., Vanderpump, M., Baldeweg, S., Drake, W., Reddy, N., Lanyon, M., Markey A., Plant, G, Powell, M., Sinha, S, Wass, J. UK guidelines for the management of pituitary apoplexy. ClinEndocrinol (Oxf) 2011 Jan 74(1);9-20. 